\title{
Breast Cancer and Sarcoidosis: Case Series and Review of the Literature
}

\author{
Jacob Chen ${ }^{a, b}$ Robert Carter III ${ }^{b}$ Daniel Maoz ${ }^{a}$ Ana Tobar ${ }^{c}$ Eran Sharon ${ }^{a} \quad$ Franklin Greif $^{a}$ \\ a Department of Surgery, Rabin Medical Center, Beilinson Campus, Petach Tikva, Sackler Faculty of Medicine, Tel Aviv University, \\ Tel Aviv, Israel; \\ bUS Army Institute of Surgical Research, Fort Sam, Houston, TX, USA; \\ c Department of Pathology, Rabin Medical Center, Beilinson Campus, Petach Tikva, Sackler Faculty of Medicine, Tel Aviv University, \\ Tel Aviv, Israel
}

\section{Established Facts}

- The presence of sarcoidosis and breast cancer in the same patient is uncommon but sarcoidosis can mimic breast cancer.

- The differential diagnosis between breast involvement of sarcoidosis and malignancy is difficult clinically and radiologically, and histologic study is necessary when this association is suspected.

\section{Novel Insights}

- We report the first case series of Jewish females affected by both sarcoidosis and breast cancer.

- Based on our clinical cases and literature review, a histologic study is highly recommended over imaging if sarcoidosis or breast cancer is suspected in a Jewish female.

\section{Keywords}

Sarcoidosis · Breast cancer - Sarcoid-like reaction

\section{Summary}

Background: Sarcoidosis is a chronic inflammatory disease of unknown etiology, which can involve different organs and systems. Accordingly, sarcoidosis can mimic breast cancer, making the differential diagnosis very difficult. Case Report: 5 patients with a diagnosis of both sarcoidosis and breast cancer followed by the Rabin Medical Center between January 1993 and June 2012 were enrolled in this study. Additionally, a comprehensive literature review which identified 104 patients diagnosed with breast cancer and sarcoidosis was carried out. In both populations reviewed, the average age at diagnosis of sarcoidosis and breast cancer was 57 years. Among the 66 patients with both sarcoidosis and breast cancer, sarcoidosis preceded breast cancer in 31 cases, followed it in 23 cases, and appeared concurrently in 10 cases. Conclusion: Based on our clinical cases and literature review, a histological study is recommended over imaging if sarcoidosis or breast cancer may be present. Furthermore, breast cancer is rarely associated with sarcoidosis or sarcoidosis-like reaction.

\section{Introduction}

Sarcoidosis is a granulomatous inflammatory disease whose exact pathogenesis is not known [1]. It is caused by alteration of the cellular immune response after exposure to an environmental, occupational, or infectious hazard [2,3], and can involve multiple

\section{KARGER}

Fax +497614520714

\section{() 2015 S. Karger GmbH, Freiburg}

1661-3791/15/0102-0137\$39.50/0
Franklin Greif, MD

Department of Surgery A, Rabin Medical Center Beilinson Campus

39 Jabotinsky St., Petach Tikva 49100, Israel fgreif@clalit.org.il 
tissues and organs, including breast tissue. Accordingly, sarcoidosis can mimic breast cancer, making the differential diagnosis very difficult.

Although sarcoidosis is considered to be a rare manifestation in breast cancer, it is conceivable that this may be an under-representation. Despite similar clinical manifestations, very little is known about the incidence of breast cancer with a subsequent diagnosis of sarcoidosis within a short ( $2-4$ years) period. Much of what is known about the clinical diagnosis and chronological connection between breast cancer and sarcoidosis, is based on a few published series [4-21].

The shared characteristics of the 2 diseases suggest that breast cancer and sarcoidosis may have a similar pathogenesis. Therefore, the present study examined all known cases from the Rabin Medical Center and those previously reported in the medical literature with the overall goal of improving patient outcomes and understanding the mechanisms that may be involved in the pathogenesis of sarcoidosis developing in patients with breast cancer. Additionally, it should be noted that this is the first report of such cases in the Jewish population.

\section{Case Description and Methodology}

\section{Clinical Cases}

We evaluated the medical records of all patients who were admitted to the Rabin Medical Center, Israel from 1993 to 2012 and had a confirmed diagnosis of both breast cancer and sarcoidosis or sarcoid-like reaction. Data extraction from the medical records included: medical history, medical images, and histological and pathological reports from breast tissue biopsies. All clinical classifications were according to the American College of Radiology (ACR) Lexicon for Mammography [22]. Pathological specimens were evaluated for the presence of non-caseating granulomas consistent with sarcoidosis and for the manifestation of proliferative breast disease.

\section{Literature Review}

Focusing on the English and French literature, we conducted a systematic PubMed search of articles published between 1951 and 2013; sarcoidosis was cross-referenced with the following search terms: sarcoid-like reaction, breast cancer, breast carcinoma, and mammary carcinoma. Our review of the literature identified 104 patients diagnosed with breast cancer and sarcoidosis ( $\mathrm{n}=$ $66)$ or sarcoid-like reaction $(\mathrm{n}=38)$ [1, 8, 13, 14, 18-21, 23-53].

Since this was a review of the literature and not a meta-analysis, no data extraction occurred. However, we recorded needed information from each source such as age, preoperative diagnosis, pathological evaluation, and treatment plan. The chronological connection of the diseases was assessed as follows: i) breast cancer 1 year prior to sarcoidosis; ii) sarcoidosis 1 year prior to breast cancer; or iii) diagnosis of both conditions within 1 year.

\section{Results}

\section{Summary of Clinical Cases}

We report 5 cases with histologically confirmed sarcoidosis and breast cancer diagnosed and treated at the Rabin Medical Center. Demographic and clinical data are summarized in table 1 (online supplemental, www.karger.com/?DOI=381324). All patients were Caucasian females with a mean age of 49.2 years (range 26-69 years) at diagnosis of sarcoidosis and 61.2 years (range 50-77 years) at diagnosis of breast cancer. All patients underwent curative surgical procedures and recovered without complications. At the time of conclusion of this study, all of these women were cancer survivors and free of breast malignancy, with a median followup of 6 years (range 1-18 years).

\section{Literature Review}

In $23(22 \%)$ patients the breast cancer diagnosis preceded the identification of sarcoidosis; in 32 (31\%) patients sarcoidosis preceded the diagnosis of breast cancer; and in $10(10 \%)$ patients both diseases developed in parallel (table 2; online supplemental, $w w w$. karger.com/?DOI=381324). The average interval between the diagnosis of sarcoidosis and breast cancer was 9 years and 6 months. When breast cancer preceded sarcoidosis, the average interval was 4 years and 8 months. Table 2 displays the findings for all of patients with both breast cancer and sarcoidosis. Median age at the time of breast cancer diagnosis was 50 years (range 28-77 years), and median age at the time of sarcoidosis diagnosis was 49 years (20-70 years). Only 1 of 66 patients was male.

The patient's race, reported in 29 patients, was Caucasian in 21 (72\%), Black in $6(21 \%)$, and Asian in 2 (7\%). Signs and symptoms of the malignancy at presentation were reported in detail in 26 patients, of whom 24 (92\%) had a self-detected mass, and 1 (4\%) had nipple retraction and a peau d'orange appearance; in $1(4 \%)$ patient the mass was detected during routine gynecologic examination.

Reported in 34 patients, mass size at presentation ranged from 1 to $7 \mathrm{~cm}$. The mass was located in the left breast in $21(57 \%)$ patients and in the right breast in $15(40 \%)$ patients; 1 (3\%) patient had bilateral breast masses. The lesions were located in the upper quadrants in 19 patients (upper outer quadrant in 10, upper inner quadrant in 5, not specified in 4), and in the lower quadrants in 3 patients; in the remaining 12 patients the location of the mass was not specified.

Diagnostic evaluation for breast cancer included mammography, ultrasound, fine-needle aspiration, and excisional biopsy. Of the 35 patients in whom mammography findings were reported, 34 had abnormalities. We assume, based on common clinical practice, that more mammograms and biopsies were performed than specified in the reviewed literature. The same is true for other diagnostic studies.

\section{Discussion}

Sarcoidosis has a tendency to present between the ages of 20 and 49 years [44]. The incidence rates vary by race and geography, being higher among African Americans [44] and populations in Northern Europe [54]. Female gender is associated with a relative risk of 1.3 [44]. Among patients with breast cancer, the female predominance appears to be higher. Only 1 of the patients with breast cancer and sarcoidosis identified in the present review was male. Our report presents the first case series among the Jewish population, in particular Ashkenazi Jewish females, where the incidence 
rate for breast cancer is higher. In US publications, the Jewish population is categorized as white or Caucasian, which could represent a potential limitation of our report.

There are several possible chronological associations that exist between breast cancer and sarcoidosis. As previously reported, breast cancer may develop in patients with sarcoidosis, sarcoidosis may develop in patients with breast cancer, the 2 diseases may develop in tandem, or breast cancer may induce a sarcoidosis-like granulomatous response [55].

Data from our medical center showed that sarcoidosis preceded breast cancer in $50 \%$ of the cases, appeared after breast cancer in $25 \%$, and occurred in tandem in $25 \%$. All breast cancer cases were managed according to common clinical practice. In all our patients, the physical findings of a mass and palpable axillary node (in 1 patient) could be attributed to either a malignancy or an inflammatory granulomatous process.

Sarcoidosis usually presents in the lungs, and is often accompanied by mediastinal or hilar lymphadenopathy [56]. One of the most frequent extrapulmonary manifestations is peripheral lymph node involvement, reportedly found in $8-15 \%$ of patients [56-58]. The possibility of axillary lymph node involvement in sarcoidosis poses a diagnostic challenge in the differentiation of sarcoidosis from suspected breast mass metastasis to the lymphatic system and warrants nodal tissue sampling in all cases.

Local inflammatory effects of sarcoidosis and sarcoid-like reaction could potentially cause technical difficulties during sentinel lymph node or axillary lymph node dissection. However, we did not encounter these problems nor were such scenarios reported in the literature.

Breast involvement is not common in sarcoidosis [55, 59], and the diagnostic and physical findings resemble those of breast cancer. Sarcoidosis and breast masses have similar features upon palpation. Imaging is also of little value in differentiating breast involvement in sarcoidosis from breast malignancy. Although most of the patients reported in the literature may be assumed to have undergone mammography or ultrasound, the majority of publications did not mention the results of imaging studies. Hence, we cannot reach conclusions regarding the effectiveness of various imaging techniques in the differential diagnosis of sarcoidosis with breast involvement and breast cancer. It is noteworthy that sarcoidosis has been reported to increase levels of CA 15-3 in some cases [60], so the presence of this biomarker might be misleading.

In our review of the literature, about one-third of patients presented with sarcoidosis before cancer and one-third had a regional sarcoid-like reaction to the cancer; in $22 \%$ the cancer presented first, and in $10 \%$ both diseases occurred within less than 1 year of each other. The interval between the diagnosis of sarcoidosis and breast cancer was considerably longer ( 9 years and 6 months) than the interval between the diagnosis of breast cancer and sarcoidosis (4 years and 8 months). This finding may suggest a lack of chronological association between the 2 pathologies, especially when malignancy precedes sarcoidosis. This is consistent with previous reports which failed to demonstrate any clear association between breast cancer and sarcoidosis [24, 25, 61]. As for other malignancies, some authors described an increased incidence of lymphoma, lung cancer, and skin cancers in patients with sarcoidosis $[14,24$, $62]$ whereas others did not $[26,63]$.

The exact nature of sarcoid-like reaction is unknown. It is usually found in proximity to the primary tumor or in its lymphatic drainage basins [13]. As sarcoid-like granulomas are histologically identical to sarcoidosis $[31,64]$, the diagnosis of sarcoid-like reaction should be based on the absence of other features of sarcoidosis. The high rate of sarcoid-like reaction among breast cancer patients in the literature highlights the importance of a thorough clinical investigation when sarcoid-like granulomas are found in the context of known breast cancer to detect the possible presence of sarcoidosis. Furthermore, sarcoid-like reaction in regional lymph nodes can conceal a metastasis and needs to be carefully evaluated [65].

In conclusion, the presence of sarcoidosis and breast cancer in the same patient is uncommon. The differentiation between breast involvement of sarcoidosis and malignancy is difficult clinically and radiologically, and histological study is necessary when this association is suspected.

\section{Online Supplementary Material}

Table 1. Rabin Medical Center case series: patients with breast cancer and sarcoidosis

Table 2. Summary of reports in the English literature of sarcoidosis and breast cancer cases (by sequence of appearance), and sarcoid-like reaction in breast cancer cases

To access the online supplemental tables, please refer to $w w w$. karger.com/?DOI=381324.

\section{Disclosure Statement}

The authors declare that they have no conflict of interest.

\section{References}

1 Chen ES, Moller DR: Etiology of sarcoidosis. Clin Chest Med 2008;29:365-377.

2 Longcope WT, Freiman DG: A study of sarcoidosis based on a combined investigation of 160 cases including 30 autopsies from The Johns Hopkins Hospital and Massachusetts General Hospital. Medicine (Baltimore) 1952;31:1-132.
Mitchell DN, Scadding JG, Heard BE, Hinson KF: Sarcoidosis: histopathological definition and clinical diagnosis. J Clin Pathol 1977;30:395-408.

4 Newman LS, Rose CS, Maier LA: Sarcoidosis. N Engl J Med 1997;336:1224-1234.

5 Nunes H, Soler P, Valeyre D: Pulmonary sarcoidosis. Allergy 2005;60:565-582
Banik S, Bishop PW, Ormerod LP, O'Brien TE: Sarcoidosis of the breast. J Clin Pathol 1986;39:446-448.

7 Bodo M, Dobrossy L, Sugar J: Boeck's sarcoidosis of the breast: cytologic findings with aspiration biopsy cytology. A case clinically mimicking carcinoma. Acta Cytol 1978;22:1-2. 
8 Gansler TS, Wheeler JE: Mammary sarcoidosis. Two cases and literature review. Arch Pathol Lab Med 1984; 108:673-675.

9 Going JJ, Anderson TJ, Wilkinson S, Chetty U: Granulomatous lobular mastitis. J Clin Pathol 1987;40:535540.

10 Reitz ME, Seidman I, Roses DF: Sarcoidosis of the breast. N Y State J Med 1985;85:262-263.

11 Ross MJ, Merino MJ: Sarcoidosis of the breast. Hum Pathol 1985; 16:185-187.

12 Urschel JD, Loewen GM, Sarpel SC: Metastatic breast cancer masquerading as sarcoidosis. Am J Med Sci 1997;314:124-125.

13 Bassler R, Birke F: Histopathology of tumor associated sarcoid-like stromal reaction in breast cancer. An analysis of 5 cases with immunohistochemical investigations. Virchows Arch A Pathol Anat Histopathol 1988; 412:231-239.

14 Brincker H, Wilbek E: The incidence of malignant tumors in patients with respiratory sarcoidosis. $\mathrm{Br} \mathrm{J}$ Cancer 1974;29:247-251.

15 Gallimore AP, George CD, Lampert IA: Subcutaneous sarcoidosis mimicking carcinoma of the breast. Postgrad Med J 1990;66:677-678.

16 Kirshy D, Gluck B, Brancaccio W: Sarcoidosis of the breast presenting as a spiculated lesion. AJR Am J Roentgenol 1999;172:554-555.

17 Rigden B: Sarcoid lesion in breast after probable sarcoidosis in lung. Br Med J 1978;2:1533-1534.

18 Shah AK, Solomon L, Gumbs MA: Sarcoidosis of the breast coexisting with mammary carcinoma. N Y State J Med 1990;90:331-333.

19 Suen JS, Forse MS, Hyland RH, Chan CK: The malignancy-sarcoidosis syndrome. Chest 1990;98:1300-1302.

20 Von Knorring J, Selroos O: Sarcoidosis with thyroid involvement, polymyalgia rheumatica and breast carcinoma. A case report. Scand J Rheumatol 1976;5:77-80.

21 Whittington R, Lazarus A, Nerenstone S, Martin A: Sarcoidosis developing during therapy for breast cancer. Chest 1986;89:762-623.

22 Breast Imaging Reporting and Data System (BI-RADS), 3rd ed. Reston, VA, American College of Radiology, 1998.

23 Chen W, Miller RA, Hebbe KA, Guron GK: Sarcoidosis and breast carcinoma: three case reports and review. ASCO Ann Meet Proc (post-meeting ed), J Clin Oncol 2004;22:867

24 Brincker H: Interpretation of granulomatous lesions in malignancy. Acta Oncol 1992;31:85-89.

25 Gorton G, Linell F: Malignant tumors and sarcoid reactions in regional lymph nodes. Acta Radiol 1957;47: 381-392.

26 Llombart A Jr, Escudero JM: The incidence and significance of epithelioid and sarcoid-like cellular reaction in the stromata of malignant tumors. A morphological and experimental study. Eur J Cancer 1970;6:545-551.

27 Oberman HA: Invasive carcinoma of the breast with granulomatous response. Am J Clin Pathol 1987;88: 718-721.

28 Prior JT: Boeck's sarcoid with coexisting carcinoma. Am J Surg 1952;83:201-204.

29 Symmers WSC: Localized tubercoloid granulomas associated with carcinomas. Am J Pathol 1951;27:493521.

30 Syrjanen KJ: Epithelioid cell granulomas in the lymph nodes draining human cancer: ultrastructural findings of a breast cancer case. Diagn Histopathol 1981;4:291-294.
31 Risbano MG, Groshong SD, Schwarz MI: Lung nodules in a woman with a history of breast cancer. Diagnosis: a sarcoid-like reaction in metastatic breast cancer. Chest 2007;132:1697-701.

32 Brincker H: Solid tumors preceding or following sarcoidosis. Med Pediatr Oncol 1987;15:82-88.

33 Clarnette RM, Trotter J, Michell PA: A case of mammary sarcoidosis. Med J Aust 1987;147:198-199.

34 Gusakova I, Lavrenkov K, Ariad S, Mermershtain W: Pulmonary sarcoidosis mimicking metastases in breast cancer patients. Onkologie 2007;30:327-328.

35 Hunsaker AR, Munden RF, Pugatch RD, Mentzer SJ: Sarcoidlike reaction in patients with malignancy. Radiology 1996;200:255-261.

36 Lower EE, Hawkins HH, Baughman RP: Breast disease in sarcoidosis. Sarcoidosis Vasc Diffuse Lung Dis 2001; 18:301-306.

37 Tolaney SM, Colson YL, Gill RR, Schulte S, Duggan MM, Shulman LN, Winer EP: Sarcoidosis mimicking metastatic breast cancer. Clin Breast Cancer. 2007;7: 804-810.

38 Askling J, Grunewald J, Eklund A, Hillerdal G, Ekbom A: Increased risk for cancer following sarcoidosis. Am J Respir Crit Care Med 1999;160:1668-1672.

39 Seersholm N, Vestbo J, Viskum K: Risk of malignant neoplasms in patients with pulmonary sarcoidosis. Thorax 1997;52:892-894.

40 Romer FK, Hommelgaard P, Schou G: Sarcoidosis and cancer revisited: a long-term follow-up study of 555 Danish sarcoidosis patients. Eur Respir J 1998;12:906912.

41 Kennedy MP, Jimenez CA, Mhatre AD, Morice RC, Eapen GA: Clinical implications of granulomatous inflammation detected by endobronchial ultrasound transbronchial needle aspiration in patients with suspected cancer recurrence in the mediastinum. J Cardiothorac Surg 2008;3:8.

42 Reich JM, Mullooly JP, Johnson RE: Linkage analysis of malignancy-associated sarcoidosis. Chest 1995;107: 605-613.

43 Van der Hoeven JJ, Krak NC, Hoekstra OS, Comans EF, Boom RP, van Geldere D, Meijer S, van der Wall E, Buter J, Pinedo HM, Teule GJ, Lammertsma AA: 18F2-fluoro-2-deoxy-d-glucose positron emission tomography in staging of locally advanced breast cancer. J Clin Oncol 2004;22:1253-1259.

44 Rybicki BA, Major M, Popovich J Jr, Maliarik MJ, Iannuzzi MC: Racial differences in sarcoidosis incidence: a 5-year study in a health maintenance organization. Am J Epidemiol 1997;145:234-241.

45 DeFilippis EM, Kagan Arleo E: New diagnosis of sarcoidosis during treatment for breast cancer, with radiologic-pathologic correlation. Clin Imaging 2013; 37:762-766.

46 Martella S, Lohsiriwat V, Barbalho DM, Della Vigna P, Bottiglieri L, Brambullo T, Gottardi A, Rietjens M, Petit JY: Sarcoid-like reaction in breast cancer: a longterm follow-up series of eight patients. Surg Today 2012;42:259-263.

47 Nishioka M, Igawa K, Yahata Y, Tani M, Katayama I: Simultaneous occurrence of dermatomyositis and systemic sarcoidosis with recurrent breast cancer. J Der matol 2012;39:485-486.

48 Bush E, Lamonica D, O'Connor T: Sarcoidosis mimicking metastatic breast cancer. Breast J 2011;17:533-535.
49 Alexandrescu DT, Kauffman CL, Ichim TE, Riordan $\mathrm{NH}$, Kabigting F, Dasanu CA: Cutaneous sarcoidosis and malignancy: an association between sarcoidosis with skin manifestations and systemic neoplasia. Dermatol Online J 2011;17:2.

50 Ito T, Okada T, Murayama K, Hanamura T, Kanai T, Mochizuki Y, Amano J, Ito K: Two cases of sarcoidosis discovered accidentally by positron emission tomography in patients with breast cancer. Breast J 2010;16: 561-563.

51 Viswanath L, Pallade S, Krishnamurthy B, Naveen T, Preethi BL, Pramod KP, Reddy O, Padma G: DarierRoussy sarcoidosis mimicking metastatic breast cancer. Case Rep Oncol 2009;2:251-254.

52 Ataergin S, Arslan N, Ozet A, Ozguven MA: Abnormal 18F-FDG uptake detected with positron emission tomography in a patient with breast cancer: a case of sarcoidosis and review of the literature. Case Rep Med 2009:785047.

53 Dragoumis DM, Tsiftsoglou AP, Assimaki AS: Pulmonary sarcoidosis simulating metastatic breast cancer. J Cancer Res Ther 2008;4:134-136.

54 Pietinalho A, Hiraga Y, Hosoda Y, Löfroos AB, Yamaguchi $\mathrm{M}$, Selroos $\mathrm{O}$ : The frequency of sarcoidosis in Finland and Hokkaido, Japan. A comparative epidemiological study. Sarcoidosis 1995;12:61-67.

55 Ojeda H, Sardi A, Totoonchie A: Sarcoidosis of the breast: implications for the general surgeon. Am Surg 2000;66:1144-1148.

56 Baughman RP, Teirstein AS, Judson MA, Rossman MD, Yeager H Jr, Bresnitz EA, DePalo L, Hunninghake G, Iannuzzi MC, Johns CJ, McLennan G, Moller DR, Newman LS, Rabin DL, Rose C, Rybicki B, Weinberger SE, Terrin ML, Knatterud GL, Cherniak R; Case Control Etiologic Study of Sarcoidosis (ACCESS) research group: Clinical characteristics of patients in a case control study of sarcoidosis. Am J Respir Crit Care Med 2001;164:1885-1889.

57 Rizzato G: Extrapulmonary presentation of sarcoidosis. Curr Opin Pulm Med 2001;7:295-297.

58 Rizzato G, Palmieri G, Agrati AM, Zanussi C: The organ-specific extrapulmonary presentation of sarcoidosis a frequent occurrence but a challenge to an early diagnosis. A 3-year-long prospective observational study. Sarcoidosis Vasc Diffuse Lung Dis 2004;21:119-126.

59 Takahashi R, Shibuya Y, Shijubo N, Asaishi K, Abe S: Mammary involvement in a patient with sarcoidosis. Intern Med 2001;40:769-771.

60 Colomer R, Ruibal A, Genollá J, Rubio D, Del Campo JM, Bodi R, Salvador L: Circulating CA 15-3 levels in the postsurgical follow-up of breast cancer patients and in non-malignant diseases. Breast Cancer Res Treat 1989;13:123-133.

61 Brincker H: Sarcoidosis and malignancy. Chest 1995; 108:1472-1474.

62 Bouros D, Hatzakis K, Labrakis H, Zeibecoglou K: Association of malignancy with diseases causing interstitial pulmonary changes. Chest 2002;121:1278-1289.

63 Shigemitsu H: Is sarcoidosis frequent in patients with cancer? Curr Opin Pulm Med 2008;14:478-480.

64 Brincker H: Sarcoid reactions in malignant tumors. Cancer Treat Rev 1986;13:147-156.

65 Lui PC, Chow LT, Tsang RK, Chan AB, Tse GM: Fine needle aspiration cytology of lymph node with metastatic undifferentiated carcinoma and granulomatous (sarcoid-like) reaction. Pathology 2004;36:273-274. 